\title{
Pasture Establishment
}

Pasture establishment involves considerations such as site preparation, time of sowing, seed mixtures, seed coating, method of sowing and subsequent management. The recommendations which follow relate mostly to the initial development of native tussock grassland.

\section{Site Preparation}

In much of the tussock grasslands, existing tussocks provide favourable microclimates for the establishment of oversown seedlings. However, dense resident vegetation can reduce both germination and survival of seedlings. This may be reduced by using large mobs of sheep or cattle or, if necessary, by burning. Complete removal of cover can expose oversown seed on the soil surface to severe environmental conditions and can result in germination failure, particularly when dry conditions follow oversowing.

In the drier environments, competition from the natural vegetation can restrict seedling survival. It may be necessary to use a herbicide to reduce competition during the establishment phase for successful establishment of species by oversowing or overdrilling.

Where danthonia (Rytidosperma species) are present, nodulation of luceme is suppressed by toxic exudates. The effect is most severe in drier environments ( $<650 \mathrm{~mm}$ rainfall), where it is necessary to kill the danthonia several months prior to oversowing.

Another consideration is the effect of soil disturbance by cultivation or earth movement for border-dyke irrigation. High country soils, at least in most potentially irrigable areas, are generally low in organic matter. Machinery movement_during preparation can cause subsoil compaction, although this seems to have only a small, direct, adverse affect on pasture production. More importantly compaction limits water holding capacity during the early years until the increase of organic matter improves the soil porosity.

\section{Time Of Sowing}

Throughout most of the high country only spring sowings should be considered because of the variable nature of autumn rainfall. With the additional hazard of loss by winter frost, establishment and growth can be severely restricted. In the lower, dry high country, autumn sowing may be an option particularly if irrigation is available.

In spring a compromise has to be struck between waiting for adequate temperature, and yet sowing sufficiently early before moisture supplies decrease later in the spring. But, again, one has to compromise between the higher temperatures desirable for seedling establishment, and higher temperature as an indicator of impending drought conditions. The optimum sowing dates will therefore range from mid-August to October, with the earliest sowing dates on those lower sunny faces most prone to early drought. Most legumes appear to have similar moderate initial germination in the various micro-sites available, but then undergo selective mortality as stresses develop in late spring -and summer. By contrast, once grasses get through the seedling stage they generally survive.

\section{Seed Mixtures}

Where sites can be fully cultivated and drilled, seed mixtures and seeding rates need be no different in the high country than elsewhere.

Initial aerial oversowing of tussock blocks should be based on clover or other legume seed at $4-6 \mathrm{~kg} / \mathrm{ha}$. Opinion is somewhat divided as to the desirable species composition. A common compromise is alsike, white clover and red clover at $2+2+2 \mathrm{~kg} / \mathrm{ha}$. Where higher fertiliser rates are used and subdivision for subsequent grazing control is good, a higher proportion of white clover can be used, especially in areas not prone to severe summer droughts. Alsike clover is more suitable for large areas of moderate fertility under extensive grazing management. Red-clover-has-the-highest-establishment-vigourand early productivity but often does not persist if grazed heavily by sheep.

Grass is usually included in the mixtures, but the proportion of seed that establishes is generally very low. Establishment rates of $1 \%$ or less are common. The use of mob stocking to open up existing vegetation and then to tread the seed into the soil is recommended. Consideration should be given to leaving the grass introduction for several years because, unless there is adequate nitrogen being transferred from legumes to the grasses, the oversowing of 
grasses will often be a waste of time and money. Plants which do establish will be nitrogen deficient and will contribute little to pasture quality and production. Consequently, sufficient $\mathrm{S}, \mathrm{P}$ and $\mathrm{M}$ must be present in the soil to ensure that the legumes are fixing adequate amounts of nitrogen.

The establishment of pasture grasses in special purpose pastures by cultivation of tussock grassland can be enhanced by the strategic use of nitrogen fertiliser. Establishment may start with nitrogen fertiliser drilled with the grass seed. Only low rates $(5-10 \mathrm{~kg} \mathrm{~N} / \mathrm{ha})$ should be used. Also, as nitrogen fertiliser restricts legume nodulation, the legume seed should be cross drilled in a separate operation. Following seedling establishment, further nitrogen, up to $50 \mathrm{~kg} \mathrm{~N} / \mathrm{ha}$ in the later summer/early autumn, will further increase grass establishment. However, the main response in grass establishment gained with nitrogen application is achieved in the second year by using up to $150 \mathrm{~kg} \mathrm{~N} / \mathrm{ha}$ in split applications during growth periods in the spring and autumn. The use of nitrogen ensures both good grass establishment and production.

\section{Inoculation And Coating}

Each legume species generally needs specific rhizobia to form nitrogen fixing nodules. The exception is that most of the common clovers are nodulated by the same Rhizobium species.

Rhizobia are absent from large areas of undeveloped tussock grassland and, in areas where they do occur, their distribution is often irregular, so inoculation of legume seed with the correct strain of rhizobia is recommended. In the absence of existing soil rhizobia, inoculation of seed with rhizobia is essential for legume establishment because, without it, seedlings fail to nodulate and will die from nitrogen deficiency.

Areas of the tussock grasslands where clover rhizobia are present have been developed by oversowing un-inoculated seed. However, the rhizobia present may be poor nitrogen fixers and inoculation is still recommended because, if the inoculant strain displaces the existing population and forms nodules, increased nitrogen fixation can occur. Rhizobia which form nodules on lucerne and those which form nodules on lotus are rare in the tussock grasslands, so these species should always be inoculated.

Rhizobia on , oversown seed are exposed to severe environmental and soil conditions between inoculation and penetration of the seedling root into the soil. Rapid death of rhizobia can occur with conventional inoculation, so techniques have been developed to improve survival of rhizobia and hence increase nodulation and establishment of seedlings.

Coating of inoculated clover and luceme seed is recommended to increase establishment and growth. Seed coating with lime reduces the death of rhizobia on the seed and raises the $\mathrm{pH}$ in the vicinity of the seedling root. Soil $\mathrm{pH}$ is critical during the brief period of nodule formation on seedlings. On the more acid tussock grassland soils ( $\mathrm{pH}$ less than 5.0), lime coating is essential for nodulation of legumes unless the more expensive broadcast lime is applied.

Runholders can inoculate and coat seed themselves in a concrete mixer, using gum arabic as adhesive and microfme lime as coating material. However, it is difficult to produce consistent, high quality coated seed by this method, so it is advisable to use effective commercially coated seed.

It is considered better to use lime coating of seed to achieve the higher $\mathrm{pH}$ required for initial inoculation than the high transport and spreading cost in the high country of general liming. In the long term, it is probably more sustainable to find acid tolerant rhizobia and legume species than general liming.

In New Zealand, coating, or pelleting grass seed is worth considering for surface sown seed. The effect of coating on grass establishment can be large on occasions (up to six times greater establishment), but results are highly inconsistent between sowings, sites and seasons. Coating probably only doubles establishment on average, and this must be discounted against the cost. The coating is effective at the early germination and seedling establishment stage and is related to moisture contact between seed and soil. In this sense, it is the physical presence of a coat and not its composition which is important, and relatively inert coating materials are suitable.

When oversowing by air, the heavier weight of coated seed will not significantly increase seed penetration through resident vegetation. Large multi-seed pellets are generally ineffective. The present lighter commercial coating of legume seed, and the heavier coating of grass seed, decreases the drift separation of the two components in aerial oversowing. 
The use of commercially coated legume seed would seem to provide an opportunity to supply nutrients in the immediate vicinity of the establishing seedling. This could be important in the tussock grasslands because of the difficulty in obtaining uniform distribution of seed and fertiliser with aerial oversowing in steep high country. The standard coating for legumes is finely ground limestone to which sulphur and molybdenum can be added on request.

The largest response is to the addition of sulphur, which can increase both establishment and vigour of legume seedlings. It is recommended for use on the low rainfall sulphur-deficient tussock grassland soils in combination with the normal sulphur topdressing.

On molybdenum-deficient soil, addition of Mo to coated seed is recommended as an alternative to Mo application in fertiliser. However, maintenance Mo application should commence with the first maintenance fertiliser dressing, and be repeated every four years thereafter.

Coating seed with insecticides is a means of limiting early loss of legume seedlings due to attacks by weevils and grasshoppers following oversowing in tussock grasslands. In lowland pasture, coating seed with fungicides can also have beneficial effects, so this practice could be worthy of further investigation in the tussock grasslands. Coating with phosphorous or nitrogen fertiliser has not been successful to date.

\section{Method Of Sowing}

Again, there is the dilemma of compromise between the relatively low cost but often poor reliability of broadcast or aerial sowing, suitable for large areas and irregular toppgraphy, and the moderate reliability of overdrilling, or the even greater reliability of full cultivation with drilling.

Where broadcast or aerial sowing is used the seed should be trampled by using heavy stocking for a short period following sowing.

With rhizobia inoculation and coating, and sulphur and phosphorus fertiliser, the establishment of clovers is now reasonably reliable from surface sowings - except for the drier areas, where it will always be chancy.

The generally very low establishment of grasses is a concern, and the question has already been raised whether it is worth including grasses in initial sowing mixtures.

Direct drilling into tussock vegetation is generally superior to broadcast sowings, particularly in the drier areas. Over recent years, results from a comparison of the different types of drill, particularly as they influence grass establishment, have been recorded. The ranking of drills from worst to best in terms of plant establishment is: hoe coulter, till seeder, single disk, triple disc, rotadrill and single pass strip seeder.. Unfortunately, operating costs probably increase in the same order.

The limitations of the different drills appear to relate to the bulk of the resident vegetation that is being overdrilled and the uniformity in sowing depth of the individual coulter when traversing irregular topography. The cultivation action of hoe coulter and till seeder drills leaves chunks of turf which do not settle back uniformly over the seed.

This effect is minimised by the greater cutting action of the rotadrill or the removal of a turf strip as done by the single pass strip seeder under development. The cultivation action of the rotadrill or the single pass strip seeder temporarily reduces the competition from the surrounding resident vegetation. The effect of closing the drill slot over the seed, or covering of the seed, is probably best with the triple disc and rotadrill or single pass strip seeder drill.

However, in dense vegetation the triple disc tends to drag plant material down into the slot, limiting contact between seed and soil. There have also been cases, when herbicides have been used on dense vegetation, where the dragging action of the disc has brought this herbicide treated vegetation into contact with the seed. Herbicide should be applied well in advance of drilling to avoid this problem.

\section{Post-Sowing Management}

The success of any oversowing or overdrilling will depend considerably on how it is managed after sowing. With broadcast oversowing, the present recommendation is to stock it very heavily immediately for up to five days following sowing, to both dislodge any seed from the vegetation and to trample it into the ground.

There is a general underestimation of the time for which a pasture requires specific spelling and other management to enhance its establishment, vigour and spread as opposed to its long-term role in livestock feeding systems. 
The decision on when and how to use new pastures should be based on the actual stage of growth and development they have. reached, rather than time as such. As a very broad generalisation, plants should be allowed to grow to at least $10 \mathrm{~cm}$ before grazing.

Figure 5 (page 9) was presented to show the production of an establishing pasture. It can also be used to estimate the establishing time.

In a warm, moist, highly fertile site of high potential production (e.g. $8-12 t \mathrm{DM} / \mathrm{ha}$ ) it is possible to establish a stand producing substantial (e.g. 2t DM/ha) yields in a few months.
However, in a dry site of low fertility, with 1tha potential, satisfactory establishment will probably take several years.

Young stock should be used to graze young pastures. The animal husbandry requirements of young stock will ensure that young pastures are leniently grazed at this stage.

Most of the initial oversowing in the high country will be very legume dominant. If grass seed has been sown, and established successfully, then periodic, brief, hard grazing will be necessary to reduce competition and to cycle nitrogen to the grasses to enhance their growth and development. 